\title{
Optimization of fuel injection control strategy for a turbocharged diesel engine under transient condition
}

\author{
Qiang Liu ${ }^{1,2, a}$, Jun Wang ${ }^{2, b}$ and Yuanfu Ding ${ }^{2, c}$ \\ ${ }^{1}$ State Key Laboratory of Automobile Simulation and Control Jilin University, Changchun 130025, \\ China \\ 2 Jilin Engineering Normal University, Changchun 130052, China \\ a78675985@qq.com, b1371985512@qq.com, 'lq200379@tom.com
}

\begin{abstract}
Keywords: vehicle diesel engine, transient condition, combustion deterioration, fuel injection control strategy, optimization

Abstract:The problem of combustion and emission in a turbocharged diesel engine under transient conditions has become an unavoidable problem under the increasingly stringent emission regulations. In order to alleviate the transient test of large amount of capital investment, the difficult test and long testing cycle problems with CA6DL2-35E3 type high pressure common rail diesel engine as the research object, in the acquisition of a large number of test data on the basis of the construction of turbocharged diesel engine under transient conditions of software Matlab/Simulink, GT-Power, STAR-CD, coupled with artificial neural network the technology, based on DSPACE control platform. Bench test and simulation verify mutually complementary research methods, and optimize the transient performance of turbocharged diesel engine. The feasibility and effectiveness of the proposed control strategy is verified through experiments.
\end{abstract}

\section{Introduction}

The diesel engine has high thermal efficiency and good fuel economy. Compared with the gasoline engine, the compression ignition method is not restricted by deflagration, the compression ratio is high, and the ignition system is not needed. The reliability is high. In the case of the same power, the torque of the diesel engine is large and the speed of the maximum power is low. It is suitable for the use of the truck. From the point of view of saving energy and reducing fuel cost, the promotion of diesel engine sedan is of great significance. In recent years, the application of advanced technologies such as electronically controlled direct injection, common rail, turbocharging, intercooling, tail gas catalytic conversion and particulate trap has further improved the comprehensive performance of diesel engine. Diesel engine emissions of greenhouse gases are low, carbon monoxide and hydrocarbon emissions are also low, but the high emission of nitrogen oxides and particulate matter is always a puzzle for diesel engine developers.

The internal combustion engine emissions on human health and environment have a great threat, therefore, all countries are almost made of vehicle emission pollutant emission limit standards, with the increasing level of medical technology and people's awareness of environmental protection, these standards are not stringent fault. At present, the most common emission standards in the world are the three major emission systems in Europe, the United States and Japan, and our country basically follows the European emission system.

China's State Environmental Protection Administration and the State Administration of Quality Supervision Inspection and Quarantine jointly drafted the "automotive compression ignition and gas fuel ignition engine and automobile exhaust emission limits and measurement methods (Chinese stage III, IV and V)" compression ignition and fuel gas ignition engine and vehicle exhaust emission limits and methods of measurement for [(III, IV, V car stage Chinese) [S] (GB17691-2005)] provisions of the value and methods of measurement of pollutant emission limit, according to different vehicle types or different control stages, using different test conditions. The test condition for diesel engine is made up of ESC (European Steady-state Cycle, steady cycle), ELR (European Load Response test, load smoke test) and ETC (European ETC, transient cycle). 
In the face of more stringent emission control laws in the future, the European Union and the neighboring countries are developing towards the integration of emissions processing devices on the control of diesel engine emissions. Means of treatment, purification and external engine through advanced integrated after example: EGR (EGR), VGT (variable geometry turbocharger), variable valve lift, high pressure common rail fuel injection, DOC (diesel oxidation catalyst), DPF (DPF), SCR (selective catalytic reduction), in response to the euro six and more stringent emission control regulations.

\section{Generation mechanism of automobile exhaust pollutants}

Carbon monoxide

$\mathrm{CO}$ is the product of incomplete combustion of gasoline, which accounts for the first component of the exhaust gas.. The incomplete combustion of fossil fuels and high temperature under the presence of $2 \mathrm{CO}+\mathrm{O}_{2}=2 \mathrm{CO}_{2}$ makes one balance, $\mathrm{CO}$ exists in all of the actual gas burner. $\mathrm{CO}$ is a colorless, tasteless, non irritating harmful gas, mainly discharged from the exhaust pipe, but also a small amount of discharged by the crankcase.

Hydrocarbons

The definition of hydrocarbon air pollutants is not strictly, it refers to all kinds of hydrocarbons and their derivatives, many varieties, usually expressed as HC (here mainly refers to the HC fuel oil tank and carburetor emission and drip and partly because of incomplete combustion and generated hydrocarbon and its derivatives). Automobile exhaust emissions without burning gasoline and incomplete combustion of hydrocarbon derivatives produced is extremely complex, including saturated and unsaturated hydrocarbons, aromatic hydrocarbon and the hydrocarbon containing oxygen derivatives (such as aldehyde and ketone), not only the composition of species, composition and changes are also great.

Nitrogen oxides

There are many kinds of nitrogen oxides, but there are harmful effects in the atmosphere, mainly NO and NO2. These two compounds are usually expressed in NOx, which is called nitrogen oxides. NOx is mainly made up of nitrogen and oxide in the air at the high temperature of the ignition of the cylinder.

\section{Research method}

The first project of diesel engine steady and transient platform, on the basis of meeting the requirement of working parameters and control parameters, proposed the establishment of multi coupling software of turbocharged diesel engine under transient conditions of the whole platform, to explore the technological means used in diesel engine system of energy saving and emission reduction of diesel engine transient performance simulation analysis of advanced control strategies of model parameters. Verify the validity of the control strategy. The technical route of the project is as follows:

1. Set up a multi software coupled turbocharged diesel engine transient whole platform

Based on the coupling technology of Matlab/Simulink, GT-Power, STAR-CD, artificial neural network and DSPACE, the whole process platform of turbocharged diesel engine is established in transient condition. In the process of transient emission modeling, ETC's typical working condition modeling idea is abstracted, and compound transient rate is introduced as input variable, and a transient emission neural network model is successfully constructed.

The research and development of the whole process control platform for turbocharged diesel engine under transient conditions can alleviate the transient condition test and research, and has many difficulties, such as large investment volume, large test difficulty and long test period.

2. A dual objective optimization control strategy for EGR step response and torque ripple

In order to improve the response speed of EGR step and EGR step to optimize the performance of working conditions for the purpose of turbocharged diesel engine transient simulation platform, the effect on EGR turbocharged diesel engine, step simulation study on the factors and the volatility of the 
torque response condition, put forward the step response of turbocharged diesel engine EGR control strategy of double objective optimization and torque fluctuation of.

3. Control strategy of adjacent position of EGR valve based on opening feedback

In order to solve the problem of turbocharged diesel engine under transient operating conditions between NOx and smoke control, the whole control platform using the turbocharged diesel engine under transient conditions, the transient soot and NOx emission trends were studied on the EGR file of the adjacent valve feedback control strategy based on soot and NOx emissions as the goal of the comprehensive optimization.

\section{Solve the technical difficulties}

1.Automotive diesel transient condition monitoring and control platform for the transient conditions of turbocharged diesel engine simulation platform for the development of pre-test data preparation and post-control strategy verification.

2. Based on a variety of advanced modeling and simulation techniques, such as Matlab / Simulink, GT-Power, STAR-CD, neural network and so on, a transient simulation platform for turbocharged diesel engine is established. Torque variable speed and other major transient conditions, and the implementation of fuel injection control, EGR valve control, etc., in order to achieve turbocharged diesel transient combustion and emission performance optimization purposes.

\section{Conclusions}

1. To set up a measurement and control platform for the transient state of vehicle diesel engine. The core of the measurement and control platform for the CA6DL2-35E3 type high pressure common rail diesel engine, it and other transient measurement and control equipment to build together to achieve millisecond A/D acquisition, can complete the sampling control, EGR control, transient control and calibration control system of turbocharged diesel engine transient working condition monitoring platform. The whole measurement and control system meets the requirements of the test and test of the main transient conditions of the turbocharged diesel engine.

2. Based on the coupling technology of Matlab/Simulink and GT-Power, a simulation platform for turbocharged diesel engine transient working condition is established. The accuracy of the simulation platform is verified through simulation and experiment comparison. On this basis, in order to optimize the transient response of air fuel ratio as the target, 3 different fuel injection control strategies are simulated.

3. Based on the transient simulation platform of turbocharged diesel engine, taking EGR step step as a breakthrough point, the influencing factors of EGR transient response and torque ripple are analyzed. A two objective optimization control strategy of transient response and torque ripple in EGR step condition is put forward. By coupling STAR-CD software, a full parameter simulation platform for turbocharged diesel engine transient working condition is built, and the influence of two step optimal control strategy of EGR step step transient response and torque fluctuation on emission performance of turbocharged diesel engine is analyzed.

For different working conditions for different EGR rate, the piecewise function expression under different EGR rates strategy given control: in the step of time, the average order maximum EGR rate jump rate reached the target EGR valve, when the valve opening to achieve the target EGR, which keeps the EGR valve opening no change. Before the opening is reached, the "integrated" EGR opening valve is used. Compared with the original linear control strategy, the strategy in the EGR response time can be shortened to $25 \% \sim 40 \%$, compared with the "up", the torque ripple can reduce $10 \% \sim 18 \%$.

On the basis of the turbocharged diesel engine transient simulation platform, coupled with STAR-CD software, construction of turbocharged diesel engines under transient conditions all the parameters of the simulation platform, and analyzes the control strategy of double objective optimization ("integrated" control strategy) effect on the emission performance: to make the 
"comprehensive" control strategy than the "linear" low NOx emission 6\%, short response time of 19\%, $11 \%$ lower emissions than the "up" Soot, late $17 \%$ generation time.

\section{Acknowledgements}

This work was financially supported by the 2017 Jilin provincial education department "13th five-year plan" Scientific research planning project (JJKH2017159KJ), 2017 Jilin Engineering Normal University Research and Development Fund Project (XYB201717) and Jilin Engineering Normal University the hovercar system design and optimization innovation team (2017205).

\section{References}

[1]Wanhua $\mathrm{Su}$, Wenbin Yu. Effects of mixing and chemical parameters on thermal efficiency in a partly premixed combustion diesel engine with near-zero emissions. [J] International Journal of Engine Research , 2012 , 13: 188-198..

[2]Ra,Y. Reitz,R.D. The application of a multicomponent droplet vaporization modelto gasoline direct injection engines[J]. International Journal of Engine Research, 2003, 4(2003): 193-218.

[3]Rakopoulos C D , Dimaratos A , et al. Evaluation of the effect of engine, load and turbocharger parameters on transient emissions of diesel engine [J]. Energy Conversion and Management , 2009 , 50(9) : 2381-2393.

[4] Development of CNG fueled engine with lean burn for small size commercial van [J]. Society of Automotive Engineers of Japan Review. 2014,4.

[5] Environmental implications of converting light gas vehicles: the Brazilian experience [J]. Energy Policy. 2014,5.

[6] International experience with compressed natural gas (CNG) as environmental friendly fuel [J]. Energy System. 2014,5.

[7] Review and recent developments of laser ignition for internal combustion engines applications

[J]. Renewable and Sustainable Energy Reviews. 2014,5.

[8] Development of a natural gas spark ignition engine for optimum performance [J]. Proceedings of the Institutetution of Mechanical Engineers D, Journal of Automobile Engineering. 2014,5.

[9] Lean burn natural gas spark ignition engine-An overview [C]. SAE Paper. 2014,5.

[10] Combustion and emission characteristics of a lean burn natural gas engine [J]. Journal of Automotive Technology. 2014,5.

[11] Development of a Mercedes-Benz natural gas engine M366LAG with a lean-burn combustion system [C]. SAE. 2014,5.

[12] Mixture formation analysis in a direct-injection NG SI engine under different injection timings [J]. Fuel. 2014,5.

[13] Direct injection of CNG on high compression ratio spark ignition engine: numerical and experimental investigation [C]. SAE Paper. 2014,5.

[14] Investigation on different injection strategies in a direct-injected turbocharged CNG-engine [C]. SAE Paper. 2014,6.

[15] Wang X G, Huang Z H. Experimental and analytical study on biodiesel and diesel spray characteris-tics under ultra-high injection pressure.International Journal of Heat and Fluid Flow , $2010,28: 659-666$ 